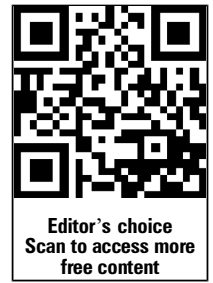

free content
Division of Respiratory Disease Studies, National Institute for Occupational Safety and Health, Centers for Disease Control and Prevention, Morgantown, West Virginia, USA

\section{Correspondence to} Dr Kristin J Cummings, National Institute for Occupational Safety and Health, Centers for Disease Control and Prevention, 1095 Willowdale Road, MS 2800, Morgantown, WV 26505, USA; kcummings@cdc.gov

Received 15 October 2013 Revised 1 May 2014 Accepted 15 May 2014 Published Online First 2 June 2014 2014;71:549-554.

\title{
Respiratory symptoms and lung function abnormalities related to work at a flavouring manufacturing facility
}

\author{
Kristin J Cummings, Randy J Boylstein, Marcia L Stanton, Chris A Piacitelli, \\ Nicole T Edwards, Ryan F LeBouf, Kathleen Kreiss
}

\section{ABSTRACT}

Objectives To better understand respiratory symptoms and lung function in flavouring manufacturing workers.

Methods We offered a questionnaire and lung function testing to the current workforce of a flavouring manufacturing facility that had transitioned away from diacetyl and towards substitutes in recent years. We examined symptoms, spirometric parameters and diffusing capacity measurements by exposure variables, including facility tenure and time spent daily in production areas. We used linear and logistic regression to develop final models adjusted for age and smoking status.

Results A total of 367 (93\%) current workers participated. Shortness of breath was twice as common in those with tenure $\geq 7$ years $(O R 2.0,95 \% \mathrm{Cl} 1.1$ to 3.6). Other chest symptoms were associated with time spent daily in production. Participants who spent $\geq 1 \mathrm{~h}$ daily in production areas had twice the odds of any spirometric abnormality (OR 2.3; 95\% Cl 1.1 to 5.3 ) and three times the odds of low diffusing capacity (OR 2.8; $95 \% \mathrm{Cl} 0.9$ to 9.4) than other participants. Mean spirometric parameters were significantly lower in those with tenure $\geq 7$ years and those who spent $\geq 1$ h daily in production. Mean diffusing capacity parameters were significantly lower in those with tenure $\geq 7$ years. Differences in symptoms and lung function could not be explained by age, smoking status or employment at another flavouring plant.

Conclusions Symptoms and lung function findings were consistent with undiagnosed or subclinical obliterative bronchiolitis and associated with workplace exposures. Further efforts to lower exposures to flavouring chemicals, including diacetyl substitutes, are warranted.

\section{INTRODUCTION}

Occupational exposure to the butter flavouring chemical diacetyl has been associated with obliterative bronchiolitis (also known as bronchiolitis obliterans) in the microwave popcorn, diacetyl manufacture and coffee processing industries. ${ }^{1-3}$ Laboratory animal models have confirmed the respiratory toxicity of diacetyl and its substitute, 2,3-pentanedione. ${ }^{4-6}$ A decade of investigation led to the formal proposal in 2011 of recommended exposure limits for diacetyl and 2,3-pentanedione in the USA. ${ }^{7}$

Far less is known about the respiratory toxicity of other diacetyl substitutes or the multitude of

\section{What this paper adds}

Flavouring manufacturing workers may be exposed to the butter flavouring chemical diacetyl, which causes obliterative bronchiolitis, and hundreds of other chemicals of unknown respiratory toxicity.

- In a facility transitioning away from diacetyl to substitutes such as 2,3-pentanedione, workers with higher flavouring chemical exposures from more time spent daily in production areas and/ or longer facility tenure had more respiratory symptoms, more lung function abnormalities and lower mean lung function parameters.

- Efforts to address adverse respiratory effects of flavouring manufacture that focus solely on diacetyl exposure reduction are unlikely to be successful. Until the safety of other flavouring chemicals is established, exposure reduction (such as through enhanced ventilation and use of respiratory protection) and medical surveillance are prudent.

other flavouring chemicals currently in use. Two cases of obliterative bronchiolitis in California flavouring manufacturing workers ${ }^{8}$ prompted industry-wide state surveillance that identified other probable cases and abnormal declines in the forced expiratory volume in $1 \mathrm{~s}\left(\mathrm{FEV}_{1}\right)$ on longitudinal spirometry. ${ }^{9}{ }^{10}$ An investigation at an Indiana flavouring manufacturing facility found an excess of spirometric restriction cross-sectionally and flavouring-related abnormal declines in $\mathrm{FEV}_{1}$ longitudinally. ${ }^{11}$ The finding of spirometric restriction could be consistent with obliterative bronchiolitis from diacetyl ${ }^{12}$ or it could represent distinct pathological effects of other exposures.

To better understand the spectrum of respiratory health in flavouring manufacturing workers, we conducted a cross-sectional study at a large flavouring manufacturing facility where obliterative bronchiolitis reportedly had been diagnosed in two former workers. Since the facility opened in 1998 , the use of diacetyl reportedly had declined and the use of substitutes had increased. Neither air sampling conducted by consultants to the facility in 2008 nor our own air sampling in 2011 detected 
diacetyl, although we did detect 2,3-pentanedione. ${ }^{13}$ Thus, results of recent industrial hygiene evaluations were consistent with a transition away from diacetyl and towards substitutes in the years prior to our study.

\section{METHODS}

\section{Study design}

The study was conducted in accordance with the NIOSH Institutional Review Board's requirements for health hazard evaluations. We invited all current workers at the facility to give written informed consent for an interviewer-administered questionnaire, spirometry and measurement of diffusing capacity. The questionnaire addressed respiratory symptoms and diagnoses, smoking history, work history and practices, and demographic information. ${ }^{13}$ The respiratory questions were adapted from validated survey instruments. ${ }^{14-16}$

We conducted and interpreted spirometry testing according to published guidelines using a dry rolling-seal spirometer. ${ }^{17-19} \mathrm{We}$ defined obstruction as $\mathrm{FEV}_{1}$ and ratio of $\mathrm{FEV}_{1}$ to forced vital capacity (FVC) below their respective lower limits of normal (5th centiles) with a normal FVC. We defined restrictive pattern as a normal $\mathrm{FEV}_{1} / \mathrm{FVC}$ ratio with $\mathrm{FVC}$ below the lower limit of normal. We classified participants with both $\mathrm{FEV}_{1} / \mathrm{FVC}$ ratio and FVC below the lower limit of normal as having mixed obstructive and restrictive abnormalities. We considered participants to have any spirometric abnormality if they met the definition of obstruction, restrictive pattern or mixed pattern.

Participants with any spirometric abnormality who did not have medical contraindications were administered a bronchodilator to determine reversibility using four puffs of a $\beta$-agonist (albuterol). We defined reversibility as an increase in $\mathrm{FEV}_{1}$ of at least $12 \%$ and $200 \mathrm{~mL}$ after bronchodilator administration. ${ }^{19}$

We measured and interpreted the diffusing capacity of the lung for carbon monoxide $\left(\mathrm{DL}_{\mathrm{CO}}\right)$ using the single breath technique with helium as the tracer gas following published guidelines. ${ }^{2021}$ We defined low diffusing capacity as $\mathrm{DL}_{\mathrm{CO}}$ below the lower limit of normal and low total lung capacity as alveolar volume below the lower limit of normal.

Following the survey, we mailed reports to each participant at his or her home address. The reports explained individual lung function test results and provided recommendations for follow-up of abnormalities.

\section{Statistical methods}

We defined asthma-like symptoms as current use of asthma medicine and/or one or more of the following symptoms in the last 12 months: wheezing or whistling in the chest, awakening with a feeling of chest tightness or attack of asthma. ${ }^{16}$ We defined work-related symptoms as those that were reported to be better away from the facility. Of note, this definition of 'work-related' is most consistent with symptoms of reversible pathologies related to occupational exposures, such as irritant and allergic effects; irreversible pathologies related to occupational exposures, such as obliterative bronchiolitis, may not demonstrate a temporal relationship to the workplace.

We calculated prevalence ratios and 95\% CIs of symptoms, diagnoses and lung function abnormalities through comparisons with data obtained from the US adult population from NHANES III ${ }^{15}$ using indirect standardisation for race (white or black), sex, age (17-39 or $\geq 40$ years) and cigarette smoking status (ever/never).

To explore potential associations between health outcomes and work, we examined questionnaire responses and lung function test results by exposure variables using contingency tables and analysis of variance to compare means. When these analyses revealed significant associations, we developed multivariable models using linear and logistic regression, adjusting for current/ former/never smoking status (for all health outcomes) and age (for health outcomes based on questionnaire responses). Most of the health outcomes based on lung function test results involve predicted values that account for age (as well as sex, height and, for spirometry, race). For analyses of the $\mathrm{FEV}_{1} / \mathrm{FVC}$ ratio, which is calculated from raw (not predicted) values, we examined the effect of age in adjusted models. For final adjusted models, we report ORs (for categorical outcomes) or least squares means (for continuous outcomes), with corresponding 95\% CI.

Exposure variables were defined on the basis of participants' self-reported work histories and categorised as follows: facility tenure ( $\geq 7$ vs $<7$ years), average amount of time spent daily in production areas $(\geq 1$ vs $<1 \mathrm{~h}$ ); use of flavouring ingredients; use of cleaning products; and history of work at another flavouring plant (including another facility owned by the same employer).

In this paper, we present comparisons of current/non-current categories. We also examined comparisons of current/never, ever/never and former/never categories, which had similar estimates.

Statistical analyses were conducted using SAS software V.9.3 and JMP software V.10.0.1 (SAS Institute, Inc, Cary, North Carolina, USA). We considered two-sided $\mathrm{p} \leq 0.05$ to be statistically significant. We used likelihood ratio tests to determine significance.

\section{RESULTS}

A total of 367 (93\%) of 393 current workers participated. All participants completed the questionnaire, and most had spirometry testing $(n=357)$ and measurement of diffusing capacity $(n=347)$. All spirometry tests and $325(94 \%)$ of the diffusing capacity tests were interpretable and included in our analyses.

The majority of participants were male $(n=231 ; 63 \%)$ and white $(\mathrm{n}=334 ; 91 \%)$. Median facility tenure was 7 years (mean 8 ; range $<1-14)$. Median time spent daily in production areas was $0 \mathrm{~h}$ (mean 2 ; range $0-10) ; 138$ (38\%) reported spending $\geq 1 \mathrm{~h}$ daily in production areas. A total of 165 (45\%) participants reported using flavouring ingredients and $211(57 \%)$ reported using cleaning products. Eighty-two (22\%) had worked at another flavouring plant.

Table 1 displays age and smoking status by time spent daily in production areas and tenure. Age was not associated with time spent daily in production areas. Participants who spent $\geq 1 \mathrm{~h}$ daily in production areas were more likely than other participants to be current smokers. Participants with tenure $\geq 7$ years were older than other participants and less likely to be current smokers.

The first column of table 1 also displays participants' responses to questions on symptoms and diagnoses. In addition, 10 participants $(3 \%)$ reported a diagnosis of chronic bronchitis and 2 reported a diagnosis of chronic obstructive pulmonary disease. One participant reported a diagnosis of bronchiolitis obliterans, but medical records were not available for review. No participant reported a diagnosis of emphysema, hypersensitivity pneumonitis or chemical pneumonitis.

Thirty $(8 \%)$ participants who had spirometry testing had an abnormal result (table 2, first column). Bronchodilator was administered to $24(80 \%)$ of those with abnormal spirometry. The majority $(n=8 ; 67 \%)$ of participants with obstruction or a mixed pattern (which may represent obstruction) had a fixed 
Table 1 Demographics, symptoms and self-reported diagnoses of participants overall and by exposure categories

\begin{tabular}{|c|c|c|c|c|c|}
\hline & \multirow[b]{2}{*}{ All participants } & \multicolumn{2}{|c|}{$\begin{array}{l}\text { Time spent daily in production } \\
\text { areas }\end{array}$} & \multicolumn{2}{|c|}{ Facility tenure } \\
\hline & & $<1 \mathrm{~h}$ & $\geq 1 \mathrm{~h}$ & $<7$ years & $\geq 7$ years \\
\hline $\mathrm{N}$ & 367 & 229 & 138 & 189 & 178 \\
\hline \multicolumn{6}{|l|}{ Demographic } \\
\hline Age, years, mean (range) & $42(20-71)$ & $42(22-71)$ & $42(20-65)$ & $37(20-66)$ & $47(27-71)$ \\
\hline \multicolumn{6}{|l|}{ Smoking status } \\
\hline Current, n (\%) & $70(19)$ & $28(12)$ & $42(30)$ & $43(23)$ & 27 (15) \\
\hline Former, n (\%) & $91(25)$ & $56(24)$ & $35(25)$ & 36 (19) & $55(31)$ \\
\hline Never, n (\%) & $206(56)$ & $145(63)$ & $61(44)$ & $110(58)$ & $96(54)$ \\
\hline \multicolumn{6}{|l|}{ Symptom* or diagnosis } \\
\hline Sinusitis, n (\%) & $174(47)$ & $100(44)$ & $74(54)$ & $87(46)$ & $87(49)$ \\
\hline WR sinusitis, n (\%) & $43(12)$ & $17(7)$ & $26(19)$ & $20(11)$ & $23(13)$ \\
\hline Nasal symptoms, n (\%) & $164(45)$ & $96(42)$ & $68(49)$ & $85(45)$ & $79(44)$ \\
\hline WR nasal symptoms, n (\%) & $55(15)$ & $26(11)$ & $29(21)$ & $31(16)$ & $24(13)$ \\
\hline Asthma-like symptoms $\dagger, \mathrm{n}(\%)$ & $101(28)$ & $52(23)$ & $49(36)$ & $55(29)$ & $46(26)$ \\
\hline Shortness of breath $\ddagger, n(\%)$ & $81(22)$ & $51(22)$ & $30(22)$ & $29(15)$ & $52(29)$ \\
\hline Wheeze, n (\%) & $82(22)$ & $45(20)$ & 37 (27) & $41(22)$ & $41(23)$ \\
\hline WR wheeze, n (\%) & $20(5)$ & $8(3)$ & $12(9)$ & $11(6)$ & $9(5)$ \\
\hline Breathing trouble, $n(\%)$ & $75(20)$ & $42(18)$ & $33(24)$ & $40(21)$ & $35(20)$ \\
\hline WR breathing trouble, $\mathrm{n}(\%)$ & $25(7)$ & $8(3)$ & $17(12)$ & $15(8)$ & $10(6)$ \\
\hline Usual phlegm, $\mathrm{n}(\%)$ & $56(15)$ & $23(10)$ & $33(24)$ & $29(15)$ & $27(15)$ \\
\hline Usual cough, n (\%) & $45(12)$ & $19(8)$ & $26(19)$ & $25(13)$ & $20(11)$ \\
\hline WR usual cough, $n(\%)$ & $12(3)$ & $4(2)$ & $8(6)$ & $6(3)$ & $6(3)$ \\
\hline Ever asthma, $\mathrm{n}(\%)$ & $44(12)$ & $28(12)$ & $16(12)$ & $25(13)$ & $19(11)$ \\
\hline Current asthma, n (\%) & $28(8)$ & $20(9)$ & $8(6)$ & $17(9)$ & $11(6)$ \\
\hline
\end{tabular}

abnormality; two of those with a fixed abnormality reported a past history of asthma and two reported current asthma. In total, $15(5 \%)$ tested participants had low diffusing capacity and $24(7 \%)$ had low total lung capacity. Most (73\%) participants with low diffusing capacity had normal spirometry; one had obstruction, two had a restrictive pattern and one had a mixed pattern. Most (67\%) participants with low total lung capacity had normal spirometry; $8(33 \%)$ had a restrictive pattern.

Table 2 Pulmonary function test results of participants overall and by exposure categories

\begin{tabular}{|c|c|c|c|c|c|}
\hline & \multirow[b]{2}{*}{ All participants } & \multicolumn{2}{|c|}{$\begin{array}{l}\text { Time spent daily in } \\
\text { production areas }\end{array}$} & \multicolumn{2}{|c|}{ Facility tenure } \\
\hline & & $<1 \mathrm{~h}$ & $\geq 1 \mathrm{~h}$ & $<7$ years & $\geq 7$ years \\
\hline Spirometry, N & 357 & 220 & 137 & 184 & 173 \\
\hline Obstruction, n (\%) & $13(4)$ & $5(2)$ & $8(6)$ & $6(3)$ & $7(4)$ \\
\hline Restrictive pattern, n (\%) & $15(4)$ & $7(3)$ & $8(6)$ & $5(3)$ & $10(6)$ \\
\hline Mixed pattern, n (\%) & $2(1)$ & 0 & $2(1)$ & 0 & $2(1)$ \\
\hline Any abnormality, $\mathrm{n}(\%)^{*}$ & $30(8)$ & $12(5)$ & $18(13)$ & $11(6)$ & $19(11)$ \\
\hline $\mathrm{FEV}_{1} \%$ predicted, mean & 99.5 & 101.3 & 96.6 & 101.5 & 97.4 \\
\hline FVC \% predicted, mean & 101.2 & 102.6 & 98.9 & 102.5 & 99.8 \\
\hline $\mathrm{FEV}_{1} / \mathrm{FVC} \%$, mean & 78.9 & 79.5 & 77.9 & 80.3 & 77.3 \\
\hline Diffusing capacity, N & 325 & 201 & 124 & 170 & 155 \\
\hline Low diffusing capacity, n (\%) & $15(5)$ & $5(2)$ & $10(8)$ & $5(3)$ & $10(6)$ \\
\hline Low total lung capacity, n (\%) & $24(7)$ & $13(6)$ & $11(9)$ & $12(7)$ & $12(8)$ \\
\hline Diffusing capacity \% predicted, mean & 95.1 & 94.9 & 95.5 & 97.0 & 93.0 \\
\hline Total lung capacity \% predicted, mean & 92.0 & 92.2 & 91.8 & 93.5 & 90.5 \\
\hline
\end{tabular}


Table 3 Adjusted* comparisons of symptoms, self-reported diagnoses and spirometric abnormalities among participants to US adult population

\begin{tabular}{|c|c|c|c|c|}
\hline & $\begin{array}{l}\text { Observed } \\
\text { (n) }\end{array}$ & $\begin{array}{l}\text { Expected } \\
\text { (n) }\end{array}$ & PR & $95 \% \mathrm{Cl}$ \\
\hline \multicolumn{5}{|l|}{ Symptom or diagnosis } \\
\hline \multicolumn{5}{|l|}{$\mathrm{N}=365$} \\
\hline Sinusitis & 172 & 136.0 & 1.3 & 1.1 to 1.5 \\
\hline Nasal symptoms & 163 & 207.3 & 0.8 & 0.7 to 0.9 \\
\hline Shortness of breath & 81 & 65.9 & 1.2 & 1.0 to 1.5 \\
\hline Wheeze & 82 & 58.1 & 1.4 & 1.1 to 1.8 \\
\hline Usual phlegm & 56 & 25.5 & 2.2 & 1.7 to 2.8 \\
\hline Usual cough & 26 & 28.1 & 0.9 & 0.6 to 1.4 \\
\hline Asthma, ever & 44 & 28.4 & 1.5 & 1.2 to 2.1 \\
\hline Asthma, current & 28 & 17.7 & 1.6 & 1.1 to 2.3 \\
\hline Chronic bronchitis, ever & 10 & 18.4 & 0.5 & 0.3 to 1.0 \\
\hline \multicolumn{5}{|l|}{ Spirometric abnormality } \\
\hline \multicolumn{5}{|l|}{$\mathrm{N}=355$} \\
\hline Obstruction & 13 & 12.6 & 1.0 & 0.6 to 1.8 \\
\hline Restrictive pattern & 15 & 25.4 & 0.6 & 0.4 to 1.0 \\
\hline Obstruction and mixed pattern & 15 & 18.7 & 0.8 & 0.5 to 1.3 \\
\hline
\end{tabular}

Results of adjusted comparisons with the US adult population are shown in table 3. Participants had higher than expected prevalence of sinusitis, wheeze, usual phlegm and asthma. Nasal symptoms and restrictive pattern on spirometry were less common than expected.

Tables 1 and 2 also display health outcomes by time spent daily in production areas and tenure. Participants who spent $\geq 1$ h daily in production areas had significantly higher prevalence of most symptoms, any spirometric abnormality and low diffusing capacity, as well as significantly lower mean spirometric parameters. Participants with $\geq 7$-year tenure had nearly twice the prevalence of shortness of breath of participants with shorter tenure and significantly lower mean spirometric and diffusing capacity parameters. Some symptoms were more common in participants who reported use of flavouring ingredients or use of cleaning products (data not shown). There were no associations between symptoms and history of work at another flavouring plant. Furthermore, there were no significant associations between lung function abnormalities or mean lung function parameters and other exposure variables.

Associations between categorical health outcomes and exposure variables seen in simple analyses were evident in adjusted regression models (table 4). Participants who spent $\geq 1 \mathrm{~h}$ daily in production areas had significantly higher odds of work-related breathing trouble, usual phlegm and any spirometric abnormality. These participants also had higher odds of asthma-like symptoms, usual cough and low diffusing capacity, although these associations did not reach statistical significance. Participants with tenure $\geq 7$ years had significantly higher odds of shortness of breath. Use of flavouring ingredients was significantly associated with work-related nasal symptoms, work-related breathing trouble and work-related usual cough. Use of cleaning products was significantly associated with work-related sinusitis and work-related nasal symptoms.

Most associations between mean pulmonary function test parameters and exposure variables noted in simple analyses were significant in regression models adjusted for smoking
Table 4 Results of adjusted models of relationship between symptoms and lung function abnormalities and exposure variables*

\begin{tabular}{|c|c|c|}
\hline Health outcome & Exposure variables & OR (95\% Cl) \\
\hline \multicolumn{3}{|l|}{ Symptom } \\
\hline Sinusitis & $\begin{array}{l}\text { Use flavourings ingredients } \\
\text { Use cleaning products }\end{array}$ & $\begin{array}{l}1.5(1.0 \text { to } 2.4) \\
1.3(0.8 \text { to } 2.1)\end{array}$ \\
\hline WR sinusitis & $\begin{array}{l}\text { Time in production areas } \\
\text { Use flavourings ingredients } \\
\text { Use cleaning products }\end{array}$ & $\begin{array}{l}1.7(0.8 \text { to } 3.5) \\
1.9(0.9 \text { to } 4.2) \\
3.0(1.3 \text { to } 8.0)\end{array}$ \\
\hline Nasal symptoms & $\begin{array}{l}\text { Use flavourings ingredients } \\
\text { Use cleaning products }\end{array}$ & $\begin{array}{l}1.4(0.9 \text { to } 2.2) \\
1.5(0.9 \text { to } 2.4)\end{array}$ \\
\hline WR nasal symptoms & $\begin{array}{l}\text { Time in production areas } \\
\text { Use flavourings ingredients } \\
\text { Use cleaning products }\end{array}$ & $\begin{array}{l}1.2(0.6 \text { to } 2.3) \\
2.2(1.1 \text { to } 4.5) \\
2.1(1.0 \text { to } 4.6)\end{array}$ \\
\hline Asthma-like symptoms & Time in production areas & $1.5(0.9$ to 2.4$)$ \\
\hline Shortness of breath & Tenure & 2.0 (1.1 to 3.6$)$ \\
\hline WR wheeze & $\begin{array}{l}\text { Time in production areas } \\
\text { Use flavourings ingredients } \\
\text { Use cleaning products }\end{array}$ & $\begin{array}{l}1.8(0.7 \text { to } 5.0) \\
2.1(0.7 \text { to } 6.7) \\
2.0(0.6 \text { to } 7.7)\end{array}$ \\
\hline WR breathing trouble & $\begin{array}{l}\text { Time in production areas } \\
\text { Use flavourings ingredients }\end{array}$ & $\begin{array}{l}2.7(1.1 \text { to } 7.1) \\
2.8(1.1 \text { to } 7.7)\end{array}$ \\
\hline Usual phlegm & $\begin{array}{l}\text { Time in production areas } \\
\text { Use flavourings ingredients } \\
\text { Use cleaning products }\end{array}$ & $\begin{array}{l}2.2(1.2 \text { to } 4.0) \\
1.4(0.7 \text { to } 2.8) \\
1.5(0.7 \text { to } 3.0)\end{array}$ \\
\hline Usual cough & Time in production areas & 1.9 (1.0 to 3.7$)$ \\
\hline WR usual cough & $\begin{array}{l}\text { Time in production areas } \\
\text { Use flavourings ingredients }\end{array}$ & $\begin{array}{l}1.8(0.5 \text { to } 7.6) \\
4.7(1.1 \text { to } 33)\end{array}$ \\
\hline \multicolumn{3}{|l|}{ Lung function abnormality } \\
\hline Any spirometric abnormality & Time in production areas & 2.3 (1.1 to 5.3$)$ \\
\hline Low diffusing capacity & Time in production areas & $2.8(0.9$ to 9.4$)$ \\
\hline
\end{tabular}

Statistically significant associations are shown in bold.

*Each model includes the exposure variables associated with the health outcome in univariable analyses. Wheeze and breathing trouble were not included in this table as they were not associated with the exposure variables in univariable analyses. Models of symptoms are adjusted for age and smoking status. Models of lung function abnormalities are adjusted for smoking status.

WR, work related.

(table 5). Both time spent daily in production areas and tenure were significantly associated with mean per cent predicted $\mathrm{FEV}_{1}$ and FVC. Tenure was significantly associated with lower mean diffusing capacity parameters. The associations with $\mathrm{FEV}_{1} / \mathrm{FVC}$ ratio were not significant after adjustment for smoking status and age.

\section{DISCUSSION}

In a flavouring manufacturing workforce without excess lung function abnormalities overall, we found consistent associations of symptoms and lung function parameters with exposure. Shortness of breath, a hallmark of chronic respiratory impairment, was significantly associated with facility tenure. The prevalence of other chest symptoms varied with time spent in production areas, and work-related cough was more common in those who used flavouring ingredients. Upper respiratory symptoms that improved away from work were associated with use of cleaning products. Lung function derangements, including spirometric abnormalities and low diffusing capacity, were more common among participants spending more time in production areas. Furthermore, mean lung function values were inversely associated with both facility tenure and time spent in production areas. Associations could not be explained by age, smoking status or employment at another flavouring plant.

Our findings of exposure-related chest symptoms, spirometric abnormalities, diffusing capacity defects and total lung capacity 
Table 5 Results of adjusted models of relationship between mean lung function parameters and exposure variables*

\begin{tabular}{|c|c|c|}
\hline Health outcome & Exposure variables & Mean $(95 \% \mathrm{Cl})$ \\
\hline \multicolumn{3}{|l|}{ Spirometry $(n=357)$} \\
\hline $\mathrm{FEV}_{1} \%$ predicted & $\begin{array}{l}\text { Time in production ar } \\
\quad<1 \mathrm{~h} \\
\geq 1 \mathrm{~h} \\
\text { Tenure } \\
\quad<7 \text { years } \\
\geq 7 \text { years }\end{array}$ & $\begin{array}{l}\text { eas } \\
100.4 \text { (98.4 to } 102.3) \\
96.4(94.2 \text { to } 98.7) \\
100.6 \text { (98.6 to } 102.7) \\
96.2 \text { (94.1 to } 98.3)\end{array}$ \\
\hline FVC $\%$ predicted & $\begin{array}{l}\text { Time in production ar } \\
\quad<1 \mathrm{~h} \\
\geq 1 \mathrm{~h} \\
\text { Tenure } \\
\quad<7 \text { years } \\
\geq 7 \text { years }\end{array}$ & $\begin{array}{l}\text { 102.8 (101.0 to } 104.6) \\
99.0(96.9 \text { to } 101.1) \\
102.3(100.4 \text { to } 104.2) \\
99.5 \text { (97.6 to } 101.4)\end{array}$ \\
\hline \multicolumn{3}{|l|}{ Diffusing capacity $(n=325)$} \\
\hline $\begin{array}{l}\text { Diffusing capacity \% } \\
\text { predicted }\end{array}$ & $\begin{array}{l}\text { Time in production ar } \\
\quad<1 \mathrm{~h} \\
\geq 1 \mathrm{~h} \\
\text { Tenure } \\
\quad<7 \text { years } \\
\geq 7 \text { years }\end{array}$ & $\begin{array}{l}\text { eas } \\
94.0 \text { (91.8 to } 96.2) \\
95.4(92.9 \text { to } 97.9) \\
97.0(94.7 \text { to } 99.2) \\
92.5(90.1 \text { to } 94.8)\end{array}$ \\
\hline $\begin{array}{l}\text { Total lung capacity } \\
\% \text { predicted }\end{array}$ & $\begin{array}{l}\text { Time in production ar } \\
\quad<1 \mathrm{~h} \\
\geq 1 \mathrm{~h} \\
\text { Tenure } \\
\quad<7 \text { years } \\
\geq 7 \text { years }\end{array}$ & $\begin{array}{l}\text { 92.6 (91.2 to } 94.1) \\
91.9(90.2 \text { to } 93.5) \\
93.8(92.3 \text { to } 95.3) \\
90.7(89.1 \text { to } 92.3)\end{array}$ \\
\hline \multicolumn{3}{|c|}{$\begin{array}{l}\text { Statistically significant differences are shown in bold. } \\
\text { *Each health outcome model includes the exposure variable(s) associated with the } \\
\text { lung function parameter in univariable analyses. Time spent in production areas was } \\
\text { not associated with diffusing capacity parameters in univariable models, but is } \\
\text { included in the final adjusted models for comparison with the spirometry models. } \\
\text { Means are least squares means adjusted for the other exposure variable and smoking } \\
\text { status. } \\
\text { FEV1, forced exploratory volume in 1s; FVC, forced vital capacity. }\end{array}$} \\
\hline
\end{tabular}

reductions indicate risk of occupational lung disease in this facility. Given the reported cases of obliterative bronchiolitis in two former workers, the recognised toxicity of diacety $1^{1-4}$ and the evolving understanding of lung function in obliterative bronchiolitis, ${ }^{22}$ these observations are most consistent with undiagnosed or subclinical obliterative bronchiolitis in the current workforce. Indeed, earlier reports of obliterative bronchiolitis in flavouring-exposed workers that emphasised fixed obstruction on spirometry and normal diffusing capacity ${ }^{1} 2{ }^{23}$ have given way to a more nuanced picture that includes a range of spirometric and diffusing capacity results. ${ }^{12} 22$ In one recent case series of biopsy-proven obliterative bronchiolitis unrelated to flavourings, a minority (5\%) had obstruction and $60 \%$ had diffusing capacity defects. ${ }^{12}$

There are several limitations to address. First, because our evaluation was cross-sectional, it was not possible to demonstrate patterns of lung function change over time. To estimate exposure, we used exposure surrogates rather than quantitative measurements, which may have allowed us to make more definitive conclusions about particular flavouring chemicals and cleaning products. It is possible that differences between participants and non-participants introduced bias, but the high participation rate (93\%) suggests our findings are representative. As we relied on participants' reports for exposure surrogates and some health outcomes, our results could be affected by reporting biases. However, systematic bias in self-report of hire date (used to calculate tenure) seems unlikely, and lung function test results are not subject to reporting bias. As such, the consistency we observed in the association between exposure and health across a variety of metrics is reassuring. Finally, we were made aware of two former workers who left employment due to lung disease, and it is possible that others may have left employment due to respiratory illness. Thus, the current workforce included in the survey may have been healthier than the entire cohort of people who had been employed at this facility. ${ }^{24}$ The absence of former workers in our survey may have obscured relationships between exposure and health outcomes that an evaluation of both current and former workers would have found. Nonetheless, even among relatively healthy current workers, the impact of exposure on health was evident.

NIOSH has proposed a recommended exposure level for diacetyl of $5 \mathrm{ppb},{ }^{7}$ which is hundreds to thousands of times lower than what was measured during prior evaluations at other flavouring manufacturing facilities. ${ }^{25-27}$ In contrast, this facility did not have documented high diacetyl exposures. However, the facility reported using amounts of diacetyl substitutes that put it in the same potential higher health risk category as California flavouring manufacturing facilities that used larger amounts of diacetyl annually. ${ }^{10}$ Our detection of 2,3-pentanedione at a concentration of $47 \mathrm{ppb}$ in a short-term sample ${ }^{13}$ is notable as the proposed short-term (15 $\mathrm{min})$ exposure limit is $31 \mathrm{ppb}$. $^{7}$ Similarly, a longer-term sample that resulted in a concentration of $26 \mathrm{ppb}^{13}$ is concerning as the proposed time-weighted average exposure limit for 2,3-pentanedione is $9.3 \mathrm{ppb}$. Our measurements, although limited, highlight what appears to be an ongoing shift in the flavouring manufacturing industry away from diacetyl and towards chemically related substitutes that may have comparable toxicity. ${ }^{5628}$ Until the safety of diacetyl substitutes has been established, these flavouring chemicals should be considered to be respiratory toxins and handled using the same controls in place for diacetyl.

Little is known about the respiratory toxicity of the many flavouring chemicals other than diacetyl and 2,3-pentanedione used at the facility. It is certainly possible that we detected not only a spectrum of physiological findings of one flavouringrelated disease, obliterative bronchiolitis, but also a spectrum of flavouring-related lung diseases. In addition to obliterative bronchiolitis, our findings could indicate risk of emphysema (obstruction and low diffusing capacity) and/or interstitial lung disease (restriction and low diffusing capacity). Despite predominantly fixed obstruction, the reported work-related pattern of some symptoms also raises the possibility of occupational or workexacerbated asthma. ${ }^{16} 29{ }^{30}$ Ultimately, distinguishing among these diagnoses would require additional evaluation, including chest imaging, bronchoprovocation testing, cardiopulmonary exercise testing and lung biopsy. Yet the possible occurrence of more than one exposure-related lung disease in this workforce and uncertainty about the chemical cause should not serve as barriers to prevention. Given that decline in lung function can occur rapidly and early in employment in flavouring-related obliterative bronchiolitis, ${ }^{3}$ 31-33 frequent medical surveillance of exposed workers that includes high-quality spirometry and close attention to declines (even within the normal range) is warranted. Furthermore, in the absence of additional toxicological information, an emphasis on exposure reduction through enhanced ventilation and use of respiratory protection is prudent.

\section{CONCLUSION}

Among current flavouring manufacturing workers, some symptoms and diagnoses were more common than expected, while spirometric abnormalities were not in excess. Symptoms, lung function abnormalities and average lung function values differed 
by exposure. These differences could not be explained by age, smoking status or employment at another flavouring plant, suggesting that they reflect outcomes of occupational exposures at the facility. These findings are most consistent with undiagnosed or subclinical obliterative bronchiolitis in this workforce and indicate that further efforts to lower exposures to flavouring chemicals, including diacetyl substitutes, are warranted.

Acknowledgements This manuscript was prepared as a part of federal employment.

Contributors All authors meet the criteria for authorship. KJC accepts full responsibility for the work and/or the conduct of the study, had access to the data and controlled the decision to publish.

Funding Supported by intramural funding from the National Institute for Occupational Safety and Health.

Competing interests None.

Patient consent Obtained.

Ethics approval NIOSH IRB.

Provenance and peer review Not commissioned; externally peer reviewed.

\section{REFERENCES}

1 Kreiss K, Gomaa A, Kullman G, et al. Clinical bronchiolitis obliterans in workers at a microwave-popcorn plant. N Engl J Med 2002;347:330-8.

2 van Rooy FG, Rooyackers JM, Prokop M, et al. Bronchiolitis obliterans syndrome in chemical workers producing diacetyl for food flavorings. Am J Respir Crit Care Med 2007; 176:498-504

3 Centers for Disease Control and Prevention (CDC). Obliterative bronchiolitis in workers in a coffee-processing facility-Texas, 2008-2012. MMWR Morb Mortal Wkly Rep 2013:62:305-7.

4 Hubbs AF, Goldsmith WT, Kashon ML, et al. Respiratory toxicologic pathology of inhaled diacetyl in Sprague-Dawley rats. Toxicol Pathol 2008;36:330-44.

5 Hubbs AF, Cumpston AM, Goldsmith WT, et al. Respiratory and olfactory cytotoxicity of inhaled 2,3-pentanedione in Sprague-Dawley rats. Am J Pathol 2012:181:829-44.

6 Morgan DL, Jokinen MP, Price HC, et al. Bronchial and bronchiolar fibrosis in rats exposed to 2,3-pentanedione vapors: implications for bronchiolitis obliterans in humans. Toxicol Pathol 2012;40:448-65.

7 NIOSH. Draft criteria for a recommended standard: occupational exposure to diacetyl and 2,3-pentanedione. U.S. Department of Health and Human Services, Centers for Disease Control and Prevention, National Institute for Occupational Safety and Health, DHHS (NIOSH) Publication No. 20XX-XXX. 12 August 2011 External Review Draft. http://www.cdc.gov/niosh/docket/archive/pdfs/NIOSH-245/ DraftDiacetylCriteriaDocument081211.pdf (accessed 6 Jun 2013).

8 Centers for Disease Control and Prevention (CDC). Fixed obstructive lung disease among workers in the flavor-manufacturing industry-California, 2004-2007. MMWR Morb Mortal Wkly Rep 2007;56:389-93.

9 Kim TJ, Materna BL, Prudhomme JC, et al. Industry-wide medical surveillance of California flavor manufacturing workers: cross-sectional results. Am J Ind Med 2010:53:857-65.

10 Kreiss $K$, Fedan $\mathrm{KB}$, Nasrullah $\mathrm{M}$, et al. Longitudinal lung function declines among California flavoring manufacturing workers. Am J Ind Med 2012;55:657-68.

11 Kreiss K. Work-related spirometric restriction in flavoring manufacturing workers. $A m$ $J$ Ind Med 2014;57:129-37.

12 King MS, Eisenberg R, Newman JH, et al. Constrictive bronchiolitis in soldiers returning from Iraq and Afghanistan. N Engl J Med 2011;365:222-30.
$13 \mathrm{NIOSH}$. Health Hazard Evaluation Report: An investigation of respiratory health at a flavoring manufacturing facility-Kentucky. U.S. Department of Health and Human Services, Public Health Service, Centers for Disease Control and Prevention, Nationa Institute for Occupational Safety and Health, NIOSH HETA No. 2012-0012-3192; 2013. http://www.cdc.gov/niosh/hhe/reports/pdfs/2012-0012-3192.pdf

14 Ferris BG. Epidemiology standardization project (American Thoracic Society). Am Rev Respir Dis 1978;118(6 Pt 2):1-120

15 Department of Health and Human Services (DHHS). National Center for Health Statistics. Third National Health and Nutrition Examination Survey, 1988-1994, NHANES III Adult and Examination Data Files (CD-ROM). Public Use Data File Documentation Number 76200. Hyattsville, MD: Centers for Disease Control and Prevention, 1996.

16 Grassi M, Rezzani C, Biino G, et al. Asthma-like symptoms assessment through ECRHS screening questionnaire scoring. J Clin Epidemiol 2003:56:238-47.

17 Miller MR, Hankinson J, Brusasco V, et al. Standardisation of spirometry. Eur Respir J 2005;26:319-38.

18 Hankinson JL, Odencrantz JR, Fedan KB. Spirometric reference values from a sample of the general U.S. population. Am J Respir Crit Care Med 1999;159:179-87.

19 Pellegrino R, Viegi G, Brusasco V, et al. Interpretative strategies for lung function tests. Eur Respir J 2005;26:948-68

20 Maclntyre N, Crapo RO, Viegi G, et al. Standardisation of the single-breath determination of carbon monoxide uptake in the lung. Eur Respir $J$ 2005:26:720-35.

21 Miller A, Thornton JC, Warshaw R, et al. Single breath diffusing capacity in a representative sample of the population of Michigan, a large industrial state. Predicted values, lower limits of normal, and frequencies of abnormality by smoking history. Am Rev Respir Dis 1983;127:270-7.

22 Kreiss K. Occupational causes of constrictive bronchiolitis. Curr Opin Allergy Clin Immunol 2013;13:167-72.

23 Kanwal R, Kullman G, Piacitelli C, et al. Evaluation of flavorings-related lung disease risk at six microwave popcorn plants. J Occup Environ Med 2006:48:149-57.

$24 \mathrm{Li} C Y$, Sung FC. A review of the healthy worker effect in occupational epidemiology. Occup Med (Lond) 1999:49:225-9.

25 NIOSH. Health Hazard Evaluation Report: Report on Severe Fixed Obstructive Lung Disease in Workers at a Flavoring Manufacturing Plant, Commerce, California. Cincinnati, OH: U.S. Department of Health and Human Services, Public Health Service, Centers for Disease Control and Prevention, National Institute for Occupational Safety and Health, NIOSH HETA No. 2006-0303-3043, 2007.

26 NIOSH. Health Hazard Evaluation Report: Gold Coast Ingredients, Inc., Commerce, California. Cincinnati, OH: U.S. Department of Health and Human Services, Public Health Service, Centers for Disease Control and Prevention, National Institute for Occupational Safety and Health, NIOSH HETA No. 2007-0033-3074, 2008.

27 Martyny JW, Van Dyke MV, Arbuckle S, et al. Diacetyl exposures in the flavor manufacturing industry. J Occup Environ Hyg 2008:5:679-88.

28 Day G, Le Bouf R, Grote A, et al. Identification and measurement of diacetyl substitutes in dry bakery mix production. J Occup Environ Hyg 2011;8:93-103.

29 Mapp CE, Boschetto P, Maestrelli P, et al. Occupational asthma. Am J Respir Crit Care Med 2005;172:280-305.

30 Henneberger PK, Redlich CA, Callahan DB, et al. An official American Thoracic Society statement: work-exacerbated asthma. Am J Respir Crit Care Med 2011:184:368-78.

31 Akpinar-Elci M, Travis WD, Lynch DA, et al. Bronchiolitis obliterans syndrome in popcorn production plant workers. Eur Respir J 2004:24:298-302.

32 Centers for Disease Control and Prevention (CDC). Fixed obstructive lung disease among workers in the flavor-manufacturing industry-California, 2004-2007. MMWR Morb Mortal Wkly Rep 2007;56:389-93.

33 Kanwal R, Kullman G, Fedan KB, et al. Occupational lung disease risk and exposure to butter-flavoring chemicals after implementation of controls at a microwave popcorn plant. Public Health Rep 2011;126:480-94. 